\title{
Is deep brain stimulation useful in Lance-Adams syndrome?
}

\author{
${ }^{1,2}$ Gülşah Öztürk $M D,{ }^{3}$ İrem Taşç $M D,{ }^{4}$ Mustafa Yavuz Samanci $M D,{ }^{5}$ Selçuk Peker $M D$ \\ ${ }^{1}$ Memorial Health Group Sisli Hospital, Neurosurgery, Istanbul; ${ }^{2}$ Istanbul Gelisim University Health \\ Sciences School; ${ }^{3}$ Malatya Turgut Özal University School of Medicine, Neurology, Malatya; ${ }^{4}$ Koc \\ University Hospital, Department of Neurosurgery, Istanbul; ${ }^{5}$ Koc University School of Medicine, \\ Department of Neurosurgery, Istanbul, Turkey
}

\begin{abstract}
Lance-Adams syndrome (LAS) is a chronic post-hypoxic myoclonus that occurs after successful cardiopulmonary resuscitation. Although many drugs are available to treat this condition, the underlying mechanism of the disease is yet to be understood. Deep brain stimulation (DBS) has been attempted and proven to be partially successful in treating LAS in several cases. Here, we present a 40-year-old woman who developed myoclonus subsequent to cardiopulmonary arrest (CPA) that occurred after her first cesarean delivery at the age of 26 years. The patient underwent implantation of bilateral globus pallidus interna (GPi)-DBS about 14 years after disease onset. Regarding Unified Myoclonus Rating Scale (UMRS), $8 \%$ and 20\% improvements were observed in action and resting myoclonus, respectively, with high-frequency stimulation as a result of the 3-year follow-up study. In this case, neuromodulation therapy applied 14 years after hypoxia-causing LAS was not sufficiently beneficial.
\end{abstract}

Keywords: Deep brain stimulation, myoclonus, cardiopulmonary resuscitation, post-hypoxic myoclonus

\section{INTRODUCTION}

Post-hypoxic myoclonus (PHM) is a rarely diagnosed disease and is difficult to treat. It is characterized by sudden, brief involuntary muscular jerking movements after cardiopulmonary resuscitation (CPR). PHM is of two types, namely acute and chronic. ${ }^{1}$ In the literature, the chronic PHM has been described as Lance Adams Syndrome (LAS)., ${ }^{2,3}$ Both the incidence and pathogenesis of the disease have not been clearly described, and only little is known about effective treatment strategies. Globally, around 150 patients have been diagnosed with LAS, and only five have been treated with bilateral globus pallidus interna-deep brain stimulation (GPi-DBS). In this article, we present an LAS case that did not benefit from bilateral GPi-DBS, unlike the five cases published in the literature. ${ }^{4-8}$

\section{CASE REPORT}

A 40-year-old woman went into cardiopulmonary arrest (CPA) during an emergency cesarean delivery at the $36^{\text {th }}$ week of pregnancy at the age of 26 years. The medical history of the patient was unremarkable, with no chronic disease and no regular medication during pregnancy. After successful resuscitation, she regained consciousness on the $7^{\text {th }}$ day. During the $2^{\text {nd }}$ week, she developed involuntary jerky movements and was treated with several drugs, but without any significant beneficial effects. She had previously been treated with clonazepam, levetiracetam, lacosamide, and sodium valproate. She was referred to our hospital 14 years after the onset of myoclonus. She experienced myoclonus both at rest and at action and could not eat or walk by herself. Her Cattel 2A culture-free mental test score was 66 , which denoted mild mental retardation. Negative and positive myoclonic jerks mostly originated from the flexor muscles in the upper and lower extremities and the abductor muscles in the trunk. Occasionally, the orbital muscles were also involved. It was observed that the myoclonic jerks became more frequent during tactile stimulation and action. More than one jerk occurred per second during action, and 1-2 times per 10 seconds at rest were recorded (Video 1). Surface electromyograms revealed a cortical and subcortical myoclonus pattern. Giant somatosensory evoked potentials were not noted in our case. 
Table 1: Preoperative and postoperative Unified Myoclonus Rating Scale (UMRS) scores

\begin{tabular}{llcc}
\hline & \multicolumn{1}{c}{ Section } & Preoperative & Postoperative $3^{\text {rd }}$ year \\
\hline 1 & Patient questionnaire & 33 & 30 \\
2 & Myoclonus at rest & 30 & 24 \\
3 & Stimulus sensitivity & 13 & 11 \\
4 & Myoclonus with action & 112 & 103 \\
5 & Functional tests & 26 & 23 \\
6 & Global disability score & 4 & 4 \\
\hline
\end{tabular}

Electroencephalogram (EEG) did not reveal any seizure activity. Magnetic resonance imaging (MRI) showed a millimetric ischemic area in the white matter in both cerebral hemispheres. Unified Myoclonus Rating Scale (UMRS) was 112 for action, 30 for rest, and 13 for stimulus sensitivity (Table 1). The patient underwent implantation of bilateral GPi-DBS about 14 years after disease onset. Stereotactic CT-derived targets to the posterolateral GPi guided the placement of the leads with the confirmation of intraoperative microelectrode recordings (MER) (Figure 1). Postoperative CT images superimposed on the preoperative MRI and we confirmed that both the leads were in the optimal position for GPi (Figure 2). The stimulation of GPi was started during the $1^{\text {st }}$ postoperative week at high frequency.
During follow-up, the DBS parameters were adjusted to different frequencies, and the best response was obtained at a high frequency. During the last programming session, the parameters were adjusted to an amplitude of $3 \mathrm{~V}$, a pulse width of $60 \mu \mathrm{s}$, and a frequency of $130 \mathrm{~Hz}$. Although a minimal decrease was observed in the extremity and eyelid myoclonus after three years, no improvement was noted in the trunk myoclonus (Video 2). The UMRS motor scores are shown in Tables 1 and 2, along with the five other published LAS-DBS cases. The medications of the patient were maintained at the same dosage.

\section{DISCUSSION}

After successful CPR, several neurological symptoms such as PHM may appear depending

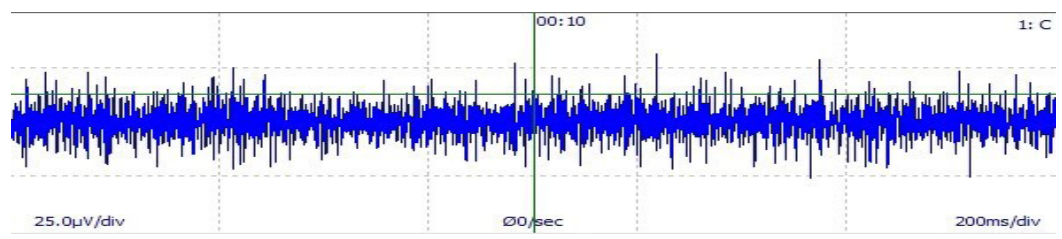

Figure 1. Peroperative microelectrode recordings of the patient; the target point for globus pallidus interna

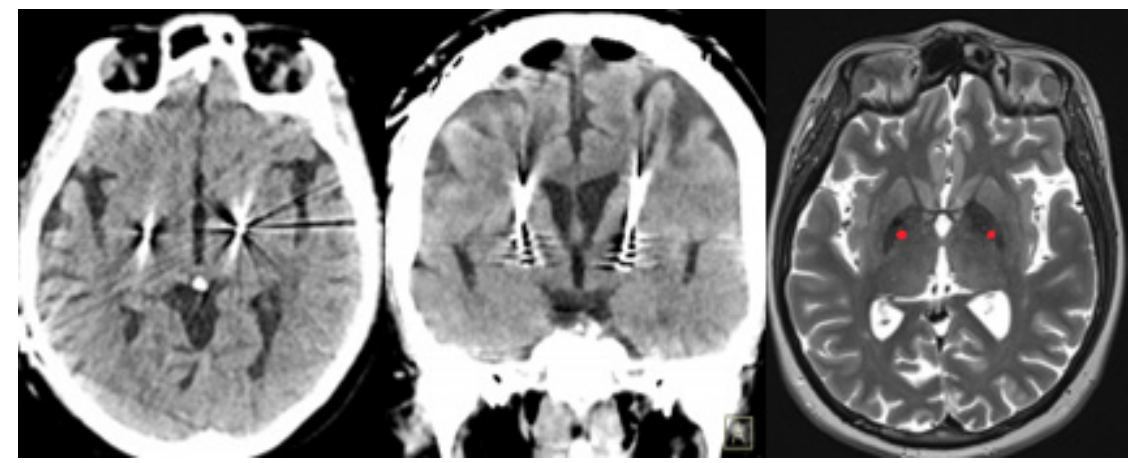

Figure 2. Postoperative CT images was fused with the preoperative MRI, and the ends of the leads were identified with red dots. 
Table 2: Published cases of Lance Adams Syndrome treated with bilateral globus pallidus internadeep brain stimulation (GPi-DBS)

\begin{tabular}{|c|c|c|c|c|c|c|c|}
\hline Study & Etiology & $\begin{array}{l}\text { Time } \\
\text { to DBS }\end{array}$ & Target & $\begin{array}{c}\text { Preoperative } \\
\text { UMRS }\end{array}$ & $\begin{array}{c}\text { Postoperative } \\
\text { UMRS }\end{array}$ & Improvement & $\begin{array}{l}\text { Follow- } \\
\text { up }\end{array}$ \\
\hline $\begin{array}{l}\text { Asahi } \\
\text { et al. } \\
(2015)^{7}\end{array}$ & $\mathrm{CPA}$ & 1 year & BL Gpi & $\begin{array}{c}\text { Action: } 25 \\
\text { Rest: } 8 \\
\text { Stimulus } \\
\text { Sensitivity: } 5\end{array}$ & $\begin{array}{c}\text { Action: } 5 \\
\text { Rest: } 0 \\
\text { Stimulus } \\
\text { Sensitivity: } 0\end{array}$ & $\begin{array}{l}\text { Action: } 80 \% \\
\text { Rest: } 100 \%\end{array}$ & $\begin{array}{c}6 \\
\text { months }\end{array}$ \\
\hline $\begin{array}{l}\text { Ramdhani } \\
\text { et al. } \\
(2017)^{8}\end{array}$ & $\begin{array}{c}\text { Asthmatic } \\
\text { attack and } \\
\text { CPA }\end{array}$ & 3 years & BL Gpi & $\begin{array}{c}\text { Action: } 52 \\
\text { Rest: } 75 \\
\text { Stimulus } \\
\text { Sensitivity: } 0\end{array}$ & $\begin{array}{c}\text { Action: } 32 \\
\text { Rest: } 0 \\
\text { Stimulus } \\
\text { Sensitivity } 0\end{array}$ & & $\begin{array}{c}6 \\
\text { months }\end{array}$ \\
\hline $\begin{array}{l}\text { Mure } \\
\text { et al. } \\
(2020)^{4}\end{array}$ & $\begin{array}{c}\text { ICA } \\
\text { rupture } \\
\text { and CPA }\end{array}$ & 1 year & BL Gpi & $\begin{array}{c}\text { Action: } 90 \\
\text { Rest: NA } \\
\text { Stimulus } \\
\text { Sensitivity: } \\
\text { NA } \\
\end{array}$ & $\begin{array}{c}\text { Action: } 24 \\
\text { Rest: NA } \\
\text { Stimulus } \\
\text { Sensitivity NA }\end{array}$ & $\begin{array}{c}\text { Action: } 73 \% \\
\text { Rest: NA }\end{array}$ & 2 years \\
\hline $\begin{array}{l}\text { Kim } \\
\text { et al. } \\
(2020)^{5}\end{array}$ & $\begin{array}{c}\text { Drowning } \\
\text { and CPA }\end{array}$ & 3 years & BL Gpi & $\begin{array}{c}\text { Action: } 80 \\
\text { Rest: } 32 \\
\text { Stimulus } \\
\text { Sensitivity: } 17\end{array}$ & $\begin{array}{c}\text { Action: } 52 \\
\text { Rest: } 3 \\
\text { Stimulus } \\
\text { Sensitivity } 8\end{array}$ & $\begin{array}{l}\text { Action: } 35 \% \\
\text { Rest:90\% }\end{array}$ & 5 years \\
\hline $\begin{array}{l}\text { Gao et al. } \\
(2020)^{6}\end{array}$ & $\begin{array}{l}\text { Drowning } \\
\text { and CPA }\end{array}$ & $\begin{array}{c}5 \\
\text { months }\end{array}$ & BL Gpi & $\begin{array}{c}\text { Action: } 61 \\
\text { Rest: } 2 \\
\text { Stimulus } \\
\text { Sensitivity: } \\
\text { NA } \\
\end{array}$ & $\begin{array}{c}\text { Action: } 40 \\
\text { Rest: } 0 \\
\text { Stimulus } \\
\text { Sensitivity NA }\end{array}$ & $\begin{array}{l}\text { Action: } 35 \% \\
\text { Rest: } 100 \%\end{array}$ & 1 year \\
\hline $\begin{array}{l}\text { Current } \\
\text { case }\end{array}$ & $\begin{array}{c}\text { During } \\
\text { delivery- } \\
\text { CPA }\end{array}$ & $\begin{array}{c}13 \\
\text { years }\end{array}$ & BL Gpi & $\begin{array}{c}\text { Action: } 112 \\
\text { Rest: } 30 \\
\text { Stimulus } \\
\text { Sensitivity: } 13\end{array}$ & $\begin{array}{c}\text { Action: } 103 \\
\text { Rest } 24 \\
\text { Stimulus } \\
\text { Sensitivity } 11\end{array}$ & $\begin{array}{c}\text { Action: } 8 \% \\
\text { Rest: } 20 \%\end{array}$ & 3 years \\
\hline
\end{tabular}

CPA: cardiopulmonary arrest; UMRS: Unified Myoclonus Rating Scale; BL: Bilateral; A: Action, R: Rest; SS: Stimulus sensitivity, NA: Not available

on the area of the hypoxic damage to the brain. ${ }^{9-10}$ The myoclonus in LAS has no steady correlation with EEG abnormalities. ${ }^{11}$ In the previously reported LAS cases, spike waves, or multiple spike activities on the EEG, or a decrease in the EEG frequency were observed. However, the EEG may also have multiple spikes followed by slow waves, and these spike waves may be accompanied frequently but not always by myoclonic jerks. ${ }^{9,12}$ Myoclonus can be triggered by sensory stimuli in certain patients. Moreover, the negative myoclonus can occur in the lower extremities, impairing the posture and resulting in falls. Other neurological symptoms such as seizures, cerebellar ataxia, and cognitive impairment are commonly seen in LAS, similar to our case. Myoclonus can be positive/negative and subcortical/cortical in the LAS. Especially, action myoclonus tends to persist for the entire life and is difficult to treat, lowering the overall function and quality of life. Medical therapies, such as levetiracetam, piracetam, clonazepam, or sodium valproate, either alone or in combination, have been used to treat LAS. In addition, new anti-myoclonic treatments promise to treat LAS. ${ }^{13}$ To date, over 150 cases have been reported in the literature. As mentioned earlier, five LAS cases have so far been treated with bilateral GPi-DBS (Table 2). GPi is the preferred target in myoclonusdystonia patients and has also been used in the previously published LAS cases; hence, we chose it in our case. Asahi et al. ${ }^{7}$ reported a case of LAS after respiratory distress-induced CPA. They reported the first bilateral GPi- DBS case. In this case, GPi-DBS, which was applied five months after the injury, yielded beneficial results. Ramdhani et al. ${ }^{8}$ were the first to review DBStreated LAS, and they stimulated bilateral GPi in an LAS patient with a CPA etiology and an interval of three years between the injury and DBS. In their 
report, they published a successful clinical result, with a $38 \%$ improvement in action myoclonus at the 6-month follow-up. Recently, Kim et al. ${ }^{5}$ reported a case involving low frequency $(110 \mathrm{~Hz})$ GPi-DBS, with an interval of three years from injury to DBS. They also published a successful clinical result, with a $35 \%$ improvement in action myoclonus at the 5-year follow-up. Mure et al. ${ }^{4}$ reported a $73 \%$ improvement in action myoclonus, with GPi-DBS, administered one year after injury in a 79-year-old LAS case with internal carotid artery (ICA) rupture and CPA. Gao et al. ${ }^{6}$ showed that bilateral GPi-DBS provided $35 \%$ benefit in action myoclonus in a 33-year-old patient with LAS of asphyxia etiology. In these five published cases, the time of brain damage that caused LAS was a maximum of three years. In our case, GPi-DBS application partially reduced distal extremity and orbital myoclonus of cortical origin, but subcortical axial myoclonus did not decrease in our patient. In our case, we did not see a significant improvement in action or resting myoclonus during the 3 -year follow-up following GPi-DBS 14 years after the injury. DBS is one of the options in the treatment of LAS; however, the procedure could not be viewed as the goldstandard. What we need to focus on here is the application of neuromodulation therapy in the early stages of the disease. We postulate that the use of neuromodulation surgery in the early period after brain injury would be beneficial.

\section{DISCLOSURE}

Financial support: None

Conflict of interest: None

\section{REFERENCES}

1. Lance JW, Adams RD. The Syndrome of Intention or Action Myoclonus as a Sequel to Hypoxic Encephalopathy. Brain 1963;86:111-36.

2. Hallett M. Physiology of human posthypoxic myoclonus. Mov Disord 2000;15 (Suppl 1):8-13.

3. Werhahn KJ, Brown P, Thompson PD, Marsden $\mathrm{CD}$. The Clinical features and prognosis of chronic posthypoxic myoclonus. Mov Disord 1997;12(2):21620.

4. Mure H, Toyoda N, Morigaki R, Fujita K, Takagi Y. Clinical outcome and intraoperative neurophysiology of the Lance-Adams Syndrome treated with bilateral deep brain stimulation of the globus pallidus internus: A case report and review of the literature. Stereotact Funct Neurosurg 2020;98(6):1-5.

5. Kim MJ, Park SH, Heo K, Chang JW, Kim JI, Chang WS. Functional neural changes after lowfrequency bilateral globus pallidus internus deep brain stimulation for post-hypoxic cortical myoclonus: Voxel-based subtraction analysis of serial positron emission. Brain Sci 2020;10(10):730.

6. Gao F, Ostrem JL, Wang DD. Treatment of posthypoxic myoclonus using pallidal deep brain stimulation placed using interventional MRI methods. Tremor Hyperkinet Mov (N Y) 2020;10:42.

7. Asahi T, Kashiwazaki D, Dougu N, et al. Alleviation of myoclonus after bilateral pallidal deep brain stimulation for Lance-Adams syndrome. J Neurol 2015;262(6):1581-3.

8. Ramdhani RA, Frucht SJ, Kopell BH. Improvement of post-hypoxic myoclonus with bilateral pallidal deep brain stimulation: A case report and review of the literature. Tremor Hyperkinet Mov (N Y) 2017;7:461.

9. Gupta HV, Caviness JN. Post-hypoxic myoclonus: Current concepts, neurophysiology, and treatment. Tremor Hyperkinet Mov (N Y) 2016;6:409.

10. Venkatesan A, Frucht S. Movement disorders after resuscitation from cardiac arrest. Neurol Clin 2006;24(1):123-32.

11. Nigam GB, Babu SS, Peter CS, Peter CS. LanceAdams syndrome: A special case of a mother. Indian $J$ Crit Care Med 2016;20(9):548-50.

12. Freund B, Sutter R, Kaplan PW. Lance-Adams syndrome in the pretargeted temperature management era. Clin EEG Neurosci 2017;48(2):130-8.

13. Lim SY, Jasti DB, Tan AH. Improvement of "bouncy gait" in Lance-Adams syndrome with perampanel. Cureus 2020;12(1):e6773. 